\title{
A EXPERIÊNCIA PSICANALİTICA: SEUS DESAFIOS E VICISSITUDES, HOJE E AMANHÃ
}

Zeferino Rocha

Mestre em

Filosofia e Teologia

pela Pontifícia

Universidade

Gregoriana de

Roma; doutor em

Psicologia pela

Universidade de

Paris X, Nanterre;

professor do

mestrado em

Psicologia Clínica

da Universidade

Católica de

Pernambuco

(Unicap); membro

fundador do Círculo

Psicanalítico de

Pernambuco.
RESUMO: Depois de descrever brevemente os pólos estruturantes da experiência humana em geral e os elementos essenciais que definem a experiência psicanalítica, discute-se o modo como Freud avaliou criticamente a psicanálise enquanto método terapêutico no decurso da evolução de sua teoria psicanalítica e, por fim, à guisa de uma breve conclusão, coloca-se a psicanálise diante dos desafios com os quais ela se defronta hoje e se confrontará amanhã.

Palavras-chave: Experiência, experiência analítica, avaliação crítica, desafios da psicanálise.

ABSTRACT: Psychoanalytical experience: its changes and challenges, today and tomorrow. After briefly describing the structuring poles from the general human experience and the essential elements that define the psychoanalytical experience, the author discusses the way as Freud critically evaluated the psychoanalysis as a therapeutic method in evolution course in his psychoanalytical theory and, finally, in a mode of a brief conclusion, puts psychoanalysis in front of the challenges that it faces today and will confront tomorrow.

Keywords: Experience, analytical experience, critical evaluation, psychoanalysis challenges.

\section{INTRODUÇÃO}

"Todo tratamento psicanalítico é uma tentativa para libertar o amor recalcado." (FREUD)

\section{A NOÇÃO DE EXPERIÊNCIA}

Começarei dizendo o que entendo por 'experiência' de um modo geral, para poder, em seguida, mais facilmente, senão definir, ao menos descrever, o que compreendo por 'experiência analítica'. É grande e complexa a variedade de acepções que o termo 'experiência' pode ter no vocabulário filosófico e numerosos os pontos de vista sob os quais pode ser estudado 
(LALANDE, 1996, p.366). Para o objetivo deste ensaio, investigarei apenas o seu sentido mais geral, no qual predomina a acepção da experiência como uma forma de saber.

\section{A experiência, uma forma de saber}

Enquanto forma de saber, a experiência humana resulta da importante aprendizagem da vida. De fato, ninguém desconhece que a vida é uma contínua e inacabada forma de aprendizagem. Enquanto vivemos, estamos sempre aprendendo e a tarefa de aprender, na vida e com a vida, é uma tarefa que não termina nunca. Viver, em última análise, talvez não seja outra coisa senão isso. Vive-se aprendendo, e aprende-se vivendo.

Para melhor penetrar o sentido da experiência enquanto forma de saber, parece-me oportuno lembrar o que ensina a etimologia da palavra. Na palavra portuguesa 'ex(peri)ência', temos o radical latino peri, que, como o seu correspondente grego peira significa 'obstáculo' e ‘dificuldade'. Este significado aparece claramente na palavra latina periculum (que significa 'perigo') e no verbo aperire (que quer dizer 'abrir'). Nos dois casos, temos a idéia de uma ação que enfrenta dificuldades ou remove obstáculos. Portanto, em sua significação etimológica, a palavra experiência quer dizer: 'vencer dificuldades', 'superar obstáculos', 'abrir novas perspectivas' e, por conseguinte, enriquecer-se e fortificar-se na luta e no sofrimento com que nos deparamos na vida.

Ésquilo, poeta trágico da Grécia antiga, foi provavelmente quem penetrou com mais profundidade no sentido da palavra experiência como forma de saber, quando imortalizou, em uma de suas tragédias, a máxima: $\pi \alpha \theta \varepsilon \imath \mu \alpha \theta$ s (atenção diagramação: letras gregas), ou seja, 'sofrer para aprender'. Temos aqui uma das mais expressivas formas da experiência trágica em relação direta com o enigma da nossa finitude e com a dor de nossos limites. Trata-se de uma 'forma de saber', que só no sofrimento se consegue. No Agamêmnon de Ésquilo, o coro canta: "Ele (Zeus) abriu aos homens as vias da sabedoria, dando-lhes como lei: $\pi \alpha \theta \varepsilon 1 \mu \alpha \theta$ os [sofrer para aprender]” (ESCHILLE, 1982, p.264-265).

[NB. Para evitar as letras gregas, a máxima pode ser transliterada assim: páthei máthos].

\section{Vivência e experiência}

Ainda como forma de saber, a palavra experiência adquire também um sentido muito sugestivo, quando se considera a etimologia de Erfahrung, com que os alemães designam a noção de experiência. Exatamente por causa do seu sentido etimológico próprio, poder-se-ia pensar numa distinção entre a vivência (Erlebnis) e a experiência (Erfahrung). Sem querer posicionar-me diante do problema que esta distinção provavelmente levanta para os estudiosos da 
experiência (KAMBARTEL, 1972, p.609-617; FOULQUIÉ, 1962, p.255-260), lembro, apenas, que no radical da palavra Erfahrung, temos o verbo fahren, que significa 'viajar', 'percorrer caminhos', 'desbravar estradas', 'descobrir novos horizontes'. Quem viaja está continuamente adquirindo novos conhecimentos e uma nova forma de saber, que o poeta definiu com a expressão: "um saber de experiência feito”. Experienciar, portanto, é mais do que vivenciar. No ato de vivenciar, os momentos passam sem que deles nos apercebamos e se perdem na superfície dos acontecimentos. Com isso não estou querendo dizer que todas as vivências necessariamente sejam efêmeras e fugazes. Ninguém ignora que existem vivências muito profundas, que tanto podem ser enriquecedoras para o sujeito, quanto traumatizantes. Há instantes intensamente vividos que podem mudar por completo o rumo de nossas vidas. Não é tanto no grau de profundidade que se deveria procurar um fundamento para a distinção entre vivência e experiência. Se existe uma diferença, seria inclinado a dizer que esta consiste no fato de que na verdadeira experiência, as próprias vivências recebem uma forma especial de estruturação interior, mediante a qual passam a fazer parte de nossas vidas, ao serem integradas, de alguma forma, à constituição de nossa subjetividade. Assim, na qualidade de formas integrantes e integradoras da subjetividade, as experiências nos marcam profundamente e, de alguma forma, nos constituem. Já se disse que somos o resultado dessas experiências, pois são elas que traçam a trajetória da história de nossas vidas.

\section{Experiência objetiva, subjetiva e intersubjetiva}

As experiências situam-se em três registros diferentes de compreensão, embora complementares, na medida que assumem a forma de uma experiência objetiva, subjetiva ou intersubjetiva. A experiência é objetiva, quando, por meio dela, entramos em relação com as coisas que constituem o nosso mundo, o mundo que nos circunda, no qual nos situamos. Ela torna-se intersubjetiva quando nos abrimos para a comunhão com os outros. Nesta relação de abertura ao outro, o nosso ser torna-se um ser-com-os-outros, um Miteinanderensein, para dizê-lo na terminologia heideggeriana. Este nosso ser-com-os-outros é sustentado, em última análise, pelo cuidado, que nos engaja a nos preocupar conosco mesmos, assumindo o projeto de atualizar nossas possibilidades existenciais, bem como nos leva a ajudar os outros a fazerem o mesmo, dando sentido às coisas, na medida que as inserimos, enquanto instrumentos, a uma das dimensões de nosso projeto existencial. A referência feita à terminologia heideggeriana não pretende, de modo algum, buscar em Heidegger uma fundamentação conceitual para nossa maneira de compreender e de distinguir a experiência. Acreditamos, no entanto, que, embora em uma perspectiva inteiramente diferente, o que Heidegger ensina sobre o Dasein, o Mitereinandersein e a Sorge na Analítica Existencial, enriquece 
sobremaneira qualquer estudo que se queira fazer sobre a experiência humana. Posto isto a respeito da natureza da experiência, perguntemo-nos, agora, quais os seus elementos estruturantes.

\section{Pólos estruturantes da experiência}

A experiência, como forma de saber, é estruturada por dois pólos essenciais: o pólo objetivo articulado ao objeto da experiência e o pólo subjetivo em que se destaca aquilo que o sujeito diz a respeito do que viveu e descobriu no encontro com os objetos. Na unidade polivalente de sua presença, o objeto diversifica-se em uma variedade infinda de possibilidades. No momento da experiência, o sujeito entra em comunhão com o objeto e o interioriza no ato de conhecer. Assim interiorizado, o objeto começa a fazer parte da sua vida e o marca na sua singularidade de sujeito.

Em seguida, pela mediação da linguagem, o sujeito traduz e comunica aos outros a riqueza daquilo que potencialmente se esconde nos objetos. Ao homem, enquanto ser que pensa e que fala, cabe o privilégio de fazer falar as coisas, ou de lhes emprestar a linguagem para que elas digam o seu segredo. E isto não é apenas um dom especial daquele que é poeta, porque também os demais seres humanos, sejam eles cientistas ou não, por meio da linguagem, revelam o segredo das coisas. Objeto e sujeito são, portanto, os pólos estruturantes da noção de experiência, sobretudo da experiência enquanto forma de saber (VAZ, 1986).

\section{Ambigüidade da experiência}

Estes pólos não são apenas estruturantes, mas marcam a experiência com uma profunda ambigüidade. No ato em que faz uma experiência, o sujeito simultaneamente se exterioriza no objeto, interioriza o objeto na sua singularidade e procura, pela linguagem, revelar o segredo que se esconde nos objetos. Ora, isto pode ser causa de uma profunda ambigüidade, porque, nem sempre o sujeito encontra palavras adequadas para traduzir a riqueza escondida no pólo-objetivo da sua experiência. Em geral, nossas palavras são muito pobres, quando procuram traduzir o segredo das coisas. Nietzsche tem razão quando diz que nossas experiências mais profundas são "experiências mudas” e não podem ser traduzidas pela linguagem instrumental de que nos servimos para nossas comunicações.

\section{Ambigüidade da experiência analítica}

Pois bem, uma ambigüidade desta natureza está na base da experiência analítica, cujo objeto é marcado com o selo do inconsciente. A linguagem humana, regida pelos mecanismos próprios do sistema pré-consciente, jamais poderá traduzir de modo adequado nos termos de um conhecimento exato, ou de um saber científico, o que se passa no inconsciente, que é regido pelos processos psíqui- 
cos primários. Isso, porém, não invalida a primazia da palavra na experiência psicanalítica. O inconsciente, ele também tem sua linguagem própria. Uma linguagem que se poderia dizer antes da linguagem, mas, nem por isso, menos linguagem. O importante é saber ouvi-la e, sobretudo, conseguir interpretá-la. Esta ambigüidade, própria da experiência analítica, exige que nos detenhamos um pouco mais para determinar-lhe a natureza e destacar suas propriedades essenciais.

\title{
A EXPERIÊNCIA PSICANALÍTICA
}

Para tentar dizer, no essencial, o que define a experiência analítica, nada melhor do que recordar a definição mais completa que Freud deixou da psicanálise. Ela encontra-se no texto "Psicanálise e teoria da libido" e é formulada da seguinte maneira:

\begin{abstract}
“A psicanálise é o nome de: 1) um método para a investigação dos processos mentais, que são quase inacessíveis por qualquer outro modo; 2) de um método (baseado nesta investigação) para o tratamento de distúrbios neuróticos; 3) e uma coleção de informações psicológicas obtidas ao longo dessas linhas e que, gradualmente, se acumula numa nova disciplina científica." (FREUD, 1923[1922]/1974, p.287)
\end{abstract}

\section{0 método analítico}

O que primeiramente Freud destaca, nesta definição da psicanálise, é que ela é um método de investigação dos processos psíquicos inconscientes, os quais, de outro modo, permaneceriam para sempre inacessíveis e desconhecidos. Foi inegavelmente no espaço da análise, onde a eficácia deste método de investigação do inconsciente pôde, antes de tudo, ser comprovada. Em um persistente e difícil trabalho, que teve um longo percurso evolutivo e que começou com o método catártico de Breuer, Freud aos poucos conseguiu definir as linhas essenciais do seu método de investigação do inconsciente. Graças a este método, a psicanálise pôde fazer constantemente, e continua fazendo, novas descobertas no campo do psiquismo. Por isso, há quem diga que o método analítico “é o coração da descoberta freudiana."

Em virtude deste seu método, a psicanálise está sempre fazendo novas descobertas no campo de suas pesquisas, e, de modo semelhante ao que se faz nas outras ciências, ela continua descobrindo novos horizontes de pesquisa e de investigação. Só depois dessas descobertas clínicas é que as teorias tentam explicações satisfatórias para o material que foi descoberto. É graças à capacidade inventiva e criadora do método, que a psicanálise, mesmo envelhecendo (como tudo o que se desenrola no tempo) tem sempre chance de rejuvenescer no 'verde' da experiência analítica. 


\section{Um novo modelo de inteligibilidade}

É sabido que Freud construiu o conjunto de teorias que compõem a metapsicologia, tendo como modelo epistêmico as ciências da natureza (Naturwissenschaften), que, no horizonte epistemológico de seu tempo, opunham-se às ciências do espírito (Geisteswissenschaften). O modelo das ciências exatas da Natureza era, então, o modelo paradigmático da ciência. Neste contexto epistemológico, as ciências exatas não eram apenas uma forma de ciência ao lado das outras, eram a ciência por excelência, a ciência propriamente dita. Daí o sonho de Freud de fazer da psicanálise uma ciência exata construída segundo o rigor do paradigma cientificista da metodologia científica dominante em sua época.

Acontece, porém, que ao construir a teoria psicanalítica a partir dos dados descobertos na experiência clínica, Freud foi simultaneamente criando um novo espaço epistemológico, no qual, pouco a pouco, adquiriu forma um novo modelo de inteligibilidade e uma nova forma de saber, inteiramente diferentes daquele que era paradigmático no seu tempo. Este novo modelo de inteligibilidade e esta nova forma de saber, um saber sob a modalidade do não-saber, criado na e pela experiência analítica, foram constituídos pelas associações livres do analisando (associações livres das quais Freud fez a regra fundamental do método analítico), as quais tiveram como contraponto a "escuta livremente flutuante" do analista. Esse novo modelo de inteligibilidade e de saber foi também criado na relação vivida no espaço da análise entre o analisando e o analista, relação esta que foi consagrada pela técnica psicanalítica com o nome de Transferência (Übertragung).

Poder-se-ia [também] lembrar que, na experiência analítica, também encontramos os dois pólos constitutivos da experiência humana em geral. De um lado, temos os 'objetos' marcados com o selo do desejo inconsciente e descobertos pela capacidade inventiva do método, e, de outro, temos a força criativa da palavra, capaz de significar e (re)significar, no dinamismo da transferência, as experiências passadas, que estão na base dos conflitos geradores dos distúrbios psíquicos. Em essência, a experiência analítica é uma experiência de linguagem. Evidentemente que esta linguagem que especifica a experiência analítica é a linguagem dos nossos desejos e de nossas fantasias inconscientes. Na experiência analítica, tudo se deve dizer e nada fazer senão dizer. Na força criativa do dizer, o diálogo analítico empenha o sujeito em um trabalho que é mais do que um 'conhecimento de si', é uma verdadeira construção, ou (re)construção, por meio da qual o sujeito tenta 'tornar-se aquilo que é', ou melhor ainda, tenta fazer 'seu' o ser que ele é.

\section{As associações livres}

Na quase 'violência' que o analisando impõe a si mesmo de dizer tudo o que lhe vem à cabeça, sem levar em consideração qualquer exigência de censura, sem fazer escolha alguma premeditada daquilo que pretende dizer, de não buscar 
razões lógicas que coloquem um pouco de ordem na desordem espontânea de sua fala livre, bem como sem levar em consideração as exigências das etiquetas sociais ou a censura da sua consciência moral; quando isto se consegue, o método analítico libera os pensamentos de suas intenções conscientes e os faz gravitar em torno de pontos de atração que são inconscientes. Precisamente para que o imaginário do cliente pudesse com mais facilidade soltar as suas asas, produzindo um modo de pensar e de falar mais livres, Freud criou o espaço da análise e, nele, optou pelo divã do paciente e pela poltrona do analista. Evitando o face-a-face no diálogo terapêutico, ele quis deixar livre o espaço da análise para que a linguagem do inconsciente mais facilmente pudesse manifestar-se e as associações livres mais facilmente pudessem ser feitas.

\section{Transferência}

Mas esse discurso do analisando não é um discurso solitário; ele é pronunciado na presença do analista, o qual — como suporte imaginário — não apenas substitui as pessoas que foram, um dia, de grande importância na vida do analisando e na história de seus conflitos, mas é também uma referência essencial, uma presença indispensável, sem a qual o analisando jamais poderia ser reconhecido na sua condição de sujeito.

Na dinâmica do jogo transferencial, o analisando trabalha as palavras do analista, atravessando-as em todos os sentidos. Freud deu o nome de Durcharbeitung, ou seja, de 'perlaboração' a este trabalho do analisando, no qual seguramente se encontra a essência mesma do trabalho analítico (FREUD, 1914/1982, p.205-206). O analista empresta provisoriamente suas palavras ao analisando (por meio das intervenções e interpretações) para que ele se coloque em condição de assumir seu discurso e fazer suas próprias descobertas no campo da análise. Na medida que o analisando encontra as palavras que permitem dar sentido às mensagens enigmáticas inscritas, desde muito cedo, em seu inconsciente, como um 'a traduzir', ou um 'a retraduzir', dando nome aos sentimentos, que até então permaneciam inominados e indeterminados e, por isso mesmo, muito mais angustiantes; na medida que o analisando é capaz de assumir seus desejos e de se assumir como sujeito desses desejos, então, e somente então, tem a experiência da análise a possibilidade de ser vivida como uma experiência de libertação e de auto-afirmação.

\section{A psicanálise, uma experiência libertadora}

Não é de admirar, portanto, que Freud tenha definido a experiência analítica como uma experiência libertadora. Para ele,

“todo tratamento psicanalítico [Jede psychoanalytische Behandlung] é uma tentativa [ist ein

Versuch] para libertar [zu befreien] o amor recalcado [die verdrängte Liebe], que encontrou 
no sintoma a incômoda solução de um compromisso [die in einem Symptom einen kümmerlichen Kompromissausweg gefunden hatte].” (FREUD, 1907/1982, p.80)

O objetivo da análise, diz Freud, é a tentativa de dar outra vez ao homem a liberdade de sua capacidade de amar e de trabalhar, capacidades estas que a 'miséria neurótica' pode comprometer.

De fato, dentre os seres, o homem é o único que pode tornar-se prisioneiro de sua própria história e de seu passado. Mas, de outra parte, nada define melhor o ser humano do que a experiência de sua liberdade na tarefa de construir sua existência. Enquanto os demais seres da natureza nascem determinados para ser aquilo que são e têm definida a trajetória de sua evolução, o homem é aquilo que ele próprio faz de sua existência. E isto só é possível porque ele é um ser livre. Todavia, numerosas são as formas de escravidão que procuram continuamente despojá-lo do dom de sua liberdade. Essas forças de escravidão tanto vêm de fora, quanto nascem de dentro do próprio homem, sem que disto ele tenha consciência. A psicanálise, enquanto experiência libertadora, procura livrar o homem desses grilhões, que ele mesmo se fabrica e se impõe no desenrolar de sua história. Esses são, de forma muito sucinta, os elementos essenciais que definem e estruturam a experiência psicanalítica. Vejamos agora a avaliação crítica que o próprio Freud fez de sua descoberta.

\section{A EXPERIÊNCIA ANALİTICA NA AVALIAÇÃO CRÍTICA DE FREUD}

Se, por um lado, Freud jamais questionou o valor terapêutico da experiência analítica, por outro, não se pode deixar de reconhecer que esta sua avaliação nem sempre foi a mesma, mas oscilou entre um otimismo inicial e uma fase pessimista, que aparece no fim de sua grande caminhada. Dir-se-ia que esta oscilação espelha, a seu modo, a curva evolutiva do seu pensamento e de sua doutrina psicanalítica.

\section{0 paradoxo freudiano}

Ninguém hoje duvida de que Freud seja um pensador paradoxal. De fato, como filho da modernidade, ele com freqüência se apresenta como um Aufklärer e acredita que a 'razão' (Die Vernunft) pode pôr ordem na desordem das paixões. Respondendo ao que lhe perguntou Einstein, em 1932, quanto à possibilidade de evitar os horrores de uma nova guerra mundial, cujo fantasma começava a angustiar o mundo, Freud escreveu: “A situação ideal naturalmente seria uma comunidade de seres humanos, que tivessem subordinado sua vida pulsional à ditadura da razão". E acrescenta: "Mas com muitíssima probabilidade isso é uma esperança utópica” (FREUD, 1933/1982, p.284).

No entanto, o Aufklärer que fala nesses termos, considera-se, ao mesmo tempo, 
um "faustiano" (FREUD, 1966, p.468) e um verdadeiro "conquistador" (FREUD, 1986, p.339), que se deu como tarefa fundamental a missão de "revolucionar os infernos", uma vez que não podia "subjugar os deuses": "Flectere si nequeo Superos, Acheronta movebor." Esta frase, tirada do "Eneida" de Virgílio e escolhida como epígrafe do livro Die Traumdeutung (1900), é, igualmente, a epígrafe de toda sua vida e de toda sua obra.

Se, por um lado, ele se empenha, com todo o rigor de um pesquisador, de um verdadeiro Forscher, para pôr um pouco de ordem no Acheronta do Id, tentando colocar um pouco do sangue de Apolo nas veias de Dionísio; por outro lado, este filho da modernidade tornou-se um dos seus mais severos críticos, quando descentrou o sujeito de sua suposta autonomia autofundante e mostrou que a maior parte da vida psíquica é inconsciente, vale dizer, não é dominada pela razão, mas regida e dinamizada pela força das pulsões e das paixões e que "o ego não é dono de sua própria casa" (FREUD, 1917 /1974, p.178).

Pois bem, quando, no paradoxo freudiano, predomina a figura do Freud Aufklärer, é compreensível que prevaleça também o juízo otimista sobre os resultados terapêuticos da experiência analítica. De fato, de início, era convicção de Freud que, quando as representações inconscientes tornavam-se conscientes sob a égide da Razão, a experiência analítica conseguia transformar a "miséria neurótica" na "infelicidade" que é comum a todo ser humano mortal e finito. E Freud não duvidava de que esta transformação era sumamente vantajosa. Tal convicção aparece no diálogo que encerra o livro Estudos sobre a histeria (1895). À paciente que lhe dizia: "De que modo o senhor pode ajudar-me, se, como o senhor próprio diz, é provável que meu sofrimento esteja relacionado às condições e vicissitudes de minha vida?", Freud responde:

“Não duvido de que, para o Destino, deveria ser mais fácil do que para mim (remediar seu sofrimento); mas a senhora convencer-se-á de que muito se terá aproveitado se conseguirmos mudar sua miséria histérica em uma infelicidade comum. Contra esta última, poderá a senhora melhor se defender com uma vida psíquica restabelecida." (FREUD, 1895/1982, p.97)

Esta visão otimista de Freud, como sugere Joel Birman, prevaleceu durante todo o primeiro período do desenvolvimento de sua obra, período que se convencionou chamar de 'primeira tópica'. Este otimismo clínico relaciona-se intimamente com um otimismo teórico, resultante da escolha metabiológica que marcou a metapsicologia até a virada dos anos 1920, escolha esta que afirmava o primado da vida sobre a morte (BIRMAN, 2000).

Para Freud, durante toda a primeira tópica, o primado da vida sobre a morte é indiscutível. A vida é o bem originário e a morte a sua perda. A este primado 
da vida segue-se o primado da razão e, sob o primado da razão, o objetivo do método terapêutico analítico era tornar consciente tudo o que era inconsciente. Após os anos 20, este quadro teórico e clínico sofre uma profunda modificação. O primado da vida é substituído pelo primado da morte. Com a introdução da pulsão de morte, Freud põe em relevo aquela tendência que é a mais fundamental de todo vivente, vale dizer, a tendência a voltar ao estado inanimado. Daí resulta que o originário não é a vida, mas a morte. O originário é o repouso absoluto do inanimado. A vida é uma perturbação deste repouso, por isso todo ser animado tende a voltar ao estado inanimado das origens. A morte passa a ser vista como o fim da vida — "O fim de toda vida é a morte (Das Ziel alles Lebens ist der Tod)" (FREUD, 1920/1982, p.248).

Todavia esta modificação radical da perspectiva teórica foi imposta pelos fatos observados na clínica. Freud nunca esqueceu a lição de seu mestre Charcot: "Olhar repetidamente os fatos (...) A Teoria é boa, mas não impede que os fatos existam" (FREUD, 1893/1969, p.22-23). E quais foram os fatos clínicos que o levaram a introduzir a pulsão de morte na teoria psicanalítica? Esses fatos foram: a experiência do fracasso no sucesso, a neurose de destino, a repetição compulsiva de certos sonhos traumatizantes, a reação terapêutica negativa e o masoquismo originário. Todo esse material clínico punha em questão o primado, até então indiscutível, do princípio do prazer, como princípio fundamental do “acontecimento psíquico” (des psyschichen Geschehens) . Foram esses fatos clínicos que motivaram Freud a repensar sua teoria, pois ficou evidente que existia "um além do princípio do prazer”. Esses fatos exigiam uma revisão da avaliação otimista do resultado e eficácia da experiência analítica.

Joel Birman acredita que depois da virada dos anos 20, Freud chegou a questionar o objetivo terapêutico da experiência analítica e que depois de introduzir a pulsão de morte, ele deixou de olhar a psicanálise como ciência. Em vez de uma ciência, a psicanálise passa a ser vista como uma ética e o ideal da cura terapêutica substituído pela tarefa do analisando de criar para si um estilo de vida. E Birman justifica sua opinião dizendo: “Face ao desamparo do sujeito na cultura, não existe cura possível, mas somente a perspectiva de constituir um estilo subjetivo que seja capaz de lidar com os conflitos insuperáveis" (BIRMAN, 1997, p.11-12).

Minha posição não é tão radical quanto a de meu amigo Joel Birman. Inegavelmente, houve uma mudança profunda na maneira de Freud ver o psiquismo e a clínica, mas não uma mudança tão drástica, a ponto de ele deixar de ver a psicanálise como ciência e de olhá-la como método terapêutico. No meu entender, Freud jamais deixou de considerar a psicanálise como ciência, nem tampouco deixou de acreditar na eficácia terapêutica do método analítico. Acredito, sim, que o sonho de fazer da psicanálise uma 'ciência exata', ou da natureza, uma 
Naturwissenschaft, este sonho ele não o sustentou até ao fim, embora nunca o tenha admitido de modo explícito. Bastaria lembrar aquela passagem do artigo “Análise terminável e interminável”, de 1937, em que um apelo explícito é feito à "metapsicologia feiticeira".

Recordemos brevemente esta passagem. Freud estava tratando do problema da “domação da pulsão" (Bändigung des Triebes), cuja finalidade é inibir, quanto ao seu objetivo, as tendências destruidoras da pulsão de morte. Esta Bändigung da pulsão não significa, porém, sua destruição, mas sua harmonização com o ego. O trabalho não é fácil, nem Freud sabe dizer com facilidade como ele se faz. "Deve-se, então, chamar a feiticeira em nosso auxílio" (So muss denn doch die Hexe dran), vale dizer, deve-se pedir o auxílio da Feiticeira metapsicologia. E Freud conclui:

“Sem especulação e teorização metapsicológicas — quase diria: fantasiar — não se consegue aqui desta vez nenhum passo a mais Infelizmente as informações da Feiticeira não são também desta vez nem muito claras nem muito minuciosas." (FREUD, 1937/1982, p.366)

Nessa passagem, ele afirma claramente que sem abrir espaço para o fantasiar, a metapsicologia não pode ir muito longe. Se no estatuto epistêmico da metapsicologia, deve haver lugar para a especulação e para o fantasiar, evidentemente não estamos mais no terreno das ciências exatas. Mas o que se desfaz neste momento não é o sonho de fazer da psicanálise uma ciência, mas o paradigma neopositivista da ciência. Freud compreendeu que a psicanálise não podia ser senão uma Spezialwissenschaft, vale dizer, uma ciência especial, criada no registro daquela nova forma de inteligibilidade e de saber, na qual a partir de suas experiências clínicas ele construiu a sua ciência metapsicológica.

Da mesma forma, é no texto de 1937 dedicado ao problema da análise terminável e interminável, que Freud parece mais pessimista diante das possibilidades terapêuticas da experiência analítica, por causa daquilo que ele chamou "o rochedo de base da castração”. Diante dele fracassariam os propósitos terapêuticos da análise. Mas vejamos o essencial do que diz este texto. Nele, são considerados dois obstáculos insuperáveis para os objetivos e fins do trabalho analítico, quando relacionado à distinção dos sexos: a ambição fálica representada pela “inveja do pênis” (Penisneid) na mulher e a resistência que o homem experimenta "contra sua posição passiva ou feminina face a outro homem (gegen seine passive oder feminine Einstellung zum anderen Mann).” Freud relaciona de imediato estas resistências ao complexo de castração e acredita que a expressão "repulsa da feminilidade” (Ablehnung der Weiblichkeit) é a "descrição correta desta tão estranha parte da vida psíquica dos seres humanos" (FREUD, 1937/1982, p.390). Portanto, aos olhos de Freud, o "rochedo de base" 
da castração é um obstáculo intransponível para o êxito da análise. É a grande pedra que está no fundo, além da qual não se pode ir.

Mas este tom pessimista é contrabalançado por uma linguagem um pouco mais otimista, que podemos ouvir em um dos seus últimos escritos, que, por sinal, ficou inacabado. Refiro-me ao capítulo sobre o Tratamento Psicanalítico no “Esboço da Psicanálise” [Abriss der Psychoanalyse]. Nele nos é dito, que na verdade existem muitos elementos que dificultam o trabalho da análise. Bastaria lembrar: a inércia psíquica, a falta de mobilidade da libido que se recusa a abandonar suas fixações, a dificuldade que acompanha o trabalho de sublimação, tudo isso tem um papel de suma importância no resultado negativo do trabalho analítico. E Freud, então, conclui:

“(...) certamente não conseguiremos sempre vencer, mas na maioria das vezes podemos ao menos compreender por que não ganhamos (...) Quem sabe, outras possibilidades de Terapia ainda imprevistas aconteçam. No momento, nada de melhor está à nossa disposição do que a Técnica psicanalítica. E, por isso, apesar de suas limitações não se deveria desprezá-la.” (FREUD, 1940 [1938]/1982, p.420-421)

O mínimo que se pode dizer é que Freud, apesar de seu evidente pessimismo, jamais perdeu de vista a dimensão terapêutica de seu método analítico. O mesmo, penso eu, deveria ser dito do que se refere ao estatuto epistêmico de sua descoberta. As mudanças e rupturas que houve no desenvolvimento tanto da teoria quanto da clínica deveriam ser vistas não como rupturas drásticas que mutuamente se excluem, mas como momentos de um pensamento dialético, no qual as rupturas não devem ser olhadas como puras negações, mas como negações que assumem o que negam em um ulterior movimento dialético sem síntese definitiva. É isto o que acontece quando, na dinâmica da evolução de seu pensamento, Freud é levado a repensar a teoria do psiquismo, das pulsões e da angústia. Que isto baste sobre a avaliação crítica que o próprio Freud fez de sua técnica psicanalítica. Perguntemo-nos, agora, o que sobre ela e sobre a psicanálise, em geral, pensam os homens de hoje, nossos contemporâneos. A psicanálise, hoje, continua sendo aquilo que Freud sonhou e desejou que ela fosse?

\section{A PSICANÁLISE, SEUS DESAFIOS E VICISSITUDES: HOJE E AMANHÃ}

O que me proponho investigar nesta última parte do trabalho é qual o lugar e quais os desafios pelos quais vem passando a psicanálise em nosso mundo contemporâneo, que alguns denominam de “moderno pós-moderno”. Não é fácil dizer o que seja esse estranho mundo, no qual, como já se disse: “deixamos de ser contemporâneos de nós mesmos”. O que mais me chama a atenção é a vontade que domina os arautos da pós-modernidade de desconstruírem os valores da 
modernidade. Anuncia-se a morte de Deus, enquanto fundamento último dos valores metafísicos e éticos da razão clássica, apregoa-se a morte do humanismo metafísico e da história e sobre os escombros de todas essas demolições, vemos surgir um niilismo que defende o sem-sentido de tudo o que existe. E como para os pós-modernos, a psicanálise freudiana foi também construída sobre os fundamentos da razão moderna, ela e sua prática clínica são também submetidas a um trabalho de desconstrução.

Não vou entrar aqui nos detalhes deste trabalho de desconstrução da psicanálise. Lembro, apenas, que muitos dos "desconstrutores pós-modernos" (e, aqui, penso especialmente em Jacques Derrida (1967) e em Richard Rorty (1991) simpatizam com a causa psicanalítica. Mesmo entre aqueles que questionam a metapsicologia freudiana no seu estatuto de ciência, muitos não são indiferentes à descoberta do Inconsciente e ao papel essencial que ela representa no movimento da cultura contemporânea. Veja-se a respeito o que escreve Zeliko Loparic (1991).

Mais uma vez valendo-me da esclarecedora análise de Joel Birman, lembro que o fascínio e o entusiasmo pela psicanálise freudiana que dominaram o cenário intelectual tanto da Europa quanto das Américas do Norte e do Sul nos anos 1950, 60 e 70, hoje já não são mais os mesmos. O tempo da moda da psicanálise, como o de toda moda ou modismo, passou. Rápido foi seu ocaso. As neurociências, a biologia, a genética e a psicologia cognitiva estão sendo, hoje, apontadas nos meios científicos norte-americanos e europeus como alternativas mais sérias do que a psicanálise para o tratamento dos distúrbios psíquicos. Tendo fracassado como ciência, a psicanálise teria se tornado objeto de 'crença' e, como tal, pode facilmente tornar-se também um objeto de 'descrença'.

A clínica psicanalítica parece também estar vivendo um momento de crise. A demanda clínica diminui dia a dia. O preço das sessões torna a experiência da análise senão impossível, ao menos muito onerosa para a maioria das pessoas de nossa sociedade. Além do mais, os críticos acusam-na de ser demasiado longa, o que não apenas torna o tratamento mais caro, mas cria laços de dependência no cliente para com o seu analista. Em um mundo, como o nosso, no qual predomina o espírito tecnológico da produtividade para atender às demandas do consumo do modo mais rápido possível; em um mundo em que as distâncias são cada vez mais reduzidas e no qual a velocidade e a rapidez vão se tornando critérios de valor e de escolha, não resta muita chance para uma terapia, cujo pressuposto básico é a não-preocupação com o tempo cronológico, porquanto sua eficácia é marcada pelo ritmo de uma outra modalidade de tempo, que é totalmente diferente do tempo cronológico; em um mundo no qual o saber técnico está desumanizando a ciência e onde predomina a ética do lucro, não há muita chance para uma terapia, cuja finalidade é modificar estruturalmente 
as pessoas, a fim de que elas possam assumir seus desejos e a construção de seu destino. Pois bem, em um mundo assim, não é de admirar que a psicanálise esteja perdendo o seu prestígio.

\section{Desafios do amanhã}

Como deve se comportar a psicanálise diante dos desafios do amanhã, se ela pretende salvaguardar o lugar que conquistou no campo das ciências humanas? Vou, à guisa de uma breve conclusão, tentar responder a esta pergunta, valendome de uma criteriosa análise que sobre a questão escreveu Carmen Da Poian em um pequeno grande artigo (DA POIAN, 1999).

Os grandes desafios são aqueles que surgem da própria situação socioeconômica desse amanhã, que, ao que tudo indica, será muito mais ainda marcado pela globalização da economia e da política, que, salvo melhor juízo, parece favorecer os mais privilegiados e castigar os menos abastados. O mundo que nos espera é um mundo em que os ricos serão cada vez mais ricos e os pobres cada vez mais pobres. O primeiro grande desafio será esse: nesse mundo quem irá beneficiar-se com a experiência da análise? A psicanálise assumir-se-á definitivamente como uma experiência terapêutica da elite, privilégio de alguns felizardos da sorte ou das injustiças sociais?

Nesse mundo do amanhã, o imaginário social também não será mais o mesmo. Nele valorizar-se-ão muito pouco o 'saber representativo' e os esforços empreendidos na finalidade de melhor compreender o sentido da vida e da pessoa humana. Da Poian pergunta: se o inconsciente é o outro e se produz na confrontação do campo do real e do social, que será o inconsciente amanhã nesse mundo do produtivismo e do consumo, de tanto individualismo e de tão pouca solidariedade, em que os vínculos intersubjetivos se perdem? Mundo do vazio interior e do colapso das identidades e do fascínio das palavras ocas; mundo objetalizado, em que o indivíduo some em um hedonismo aniquilante, colocando nos objetos a possibilidade de sua própria constituição, enquanto sujeito.

E aqui aparece um outro grande desafio para a psicanálise de amanhã: Como se comportará a psicanálise diante das grandes questões que atingem a sexualidade como a epidemia da Aids, a emancipação da homossexualidade, as mudanças na família e nas imagens paterna e materna e as drogas? Ou a psicanálise se confronta com esses desafios, ou será descartada como um saber improdutivo e inútil. E o que deve ela fazer para poder assumir tais desafios? Repensando a teoria e alargando a escuta clínica (DA POAIN, 1999, p.28-29). Repensar a teoria é repensar os modelos de subjetivação; abrir-se para as disciplinas que estão engajadas em pensar o problema do homem e de sua inserção no mundo. Não dissociar o inconsciente do imaginário social, no qual ele se nutre e se forma. Repensar a questão dos ideais. Olhar a psicanálise como uma forma de saber 'em mutação' e 
não como um saber sistematizado e estabelecido. É ter coragem de trabalhar não apenas o que a psicanálise diz sobre as novas patologias da contemporaneidade, mas também de perguntar o que estas patologias têm a dizer à psicanálise, no sentido de lhe impor a tarefa de repensar a teoria e ampliar a escuta.

Alargar a escuta clínica significa escutar o universo próprio de cada cliente e repensar a interpretação "utilizando-a em relação a novos referenciais e novas relações mais amplas e mais atuais, dentro das quais o inconsciente continua a ser produzido. Ou ainda: "abrir pela interpretação o campo da criatividade, apontando mais para o desejo revestido de projetos do que para a falta que o origina". Alargar a escuta, respeitando, porém, o método no que ele tem de essencial, ou seja, a circulação da palavra livre pronunciada na presença do analista, transformando as repetições das vivências transferenciais na produção de uma nova maneira de ser. Estes são os desafios. Enfrentá-los e vencê-los é o que vai decidir do futuro da psicanálise.

Recebido em 9/11/2006. Aprovado em 6/4/2007.

\section{REFERÊNCIAS}

BIRMAN, J. (2000) A dádiva e o Outro. Sobre o conceito de desamparo no discurso freudiano. Anais do V Fórum Brasileiro de Psicanálise. Recife (PE), setembro de 2000.

(1997) "Sobre o mal-estar na modernidade", in Estilo e Modernidade em psicanálise. São Paulo: Editora 34.

DA POIAN, C. (1996) O futuro da psicanálise. Boletim de Novidades. Pulsional, Centro de Psicanálise, ano IX, n.81. São Paulo: Livraria Pulsional, p. $25-28$.

DERRIDA, J. (1967) “Freud et la scène de l'écriture", in L'écriture et la différence. Paris: Seuil.

ÉSQUILO (1982) “Agamêmnon”, in Tagédies. Trad. de Paul Manzon. Paris: Gallimard.

FOULQUIÉ, P. (1962) Dictionnaire de la Langue Philosophique. Paris: Presses Universitaires de France.

FREUD, S. (1893/1976) “Charcot”. Standard Brasileira, v.III. Rio de Janeiro: Imago, p.19-34.

. (1895/1982) “Zur Psychotherapie der Hysterie”. Studienausgabe. Ergänzungsband. Schriften zur Behandlungstechnik. Frankfurt am Main: Fischer, Taschenbuch Verlag, s.39-97.

(1907/1982) "Der Wahn und die Träume in W. Jensens ‘Gra-

diva”. Studienausgabe. Band X. Bildende Kunst und Literatur. Frankfurt am Main: Fischer, Taschenbuch Verlag, s. 9-85. 
(1914/1982) “Erinern, Wiederholen und Durcharbeiten — Weitere Ratschläge zur Technik der Psychoanalyse - II”. Studienausgabe. Ergänzungsband. Schriften zur Behandlungstechnik. Frankfurt am Main: Fischer Taschenbuch Verlag, s. 205-215.

. (1917/1976) "Uma dificuldade no caminho da psicanálise". Standard brasileira. v.XVII, Rio de Janeiro, Imago, p.169-179.

(1923[1922]/1976) "Dois verbetes de enciclopédia : Psicanálise

e Teoria da Libido”. Standard brasileira. v.XVIII. Rio de Janeiro; Imago, p.285-307.

(1933/1982) “Warum Krieg?”. Studienausgabe. Band IX. Fragen der Gesellschaft Ursprünge der Religion. Frankfurt am Main; Fischer, Taschenbuch Verlag, s.271-286.

. (1937/1982) "Die endliche und die unendliche Analyse". Ergänzungsband. Frankfurt am Main: Fischer, Tascenbuch Verlag, s.351- 392 .

. (1940[1938]/1982) "Die Psychoanalytische Technik — Aus der Abriss der Psychoanalyse”. Ergänzungsband. Frankfurt am Main: Fischer Taschenbuch Verlag, s.407-421.

. (1966) Correspondance 1873-1939. Paris: Gallimard.

(1986) A correspondência completa de Sigmund Freud para W. Fliess. 1887-1904. Editado por Jeffrey Moussaieff Masson. Rio de Janeiro: Imago.

LALANDE, A. (1996) Vocabulário técnico e crítico da filosofia. Tradução Fátima Correa et al. São Paulo: Martins Fontes.

LOPARIC, Z. (1991) “Um olhar epistemológico sobre o inconsciente freudiano”, in KNOBLOCH, F. (org.). O inconsciente. Várias leituras. São Paulo: Escuta.

ROCHA, Z. (1995) “A leitura de Freud e o ensino da psicanálise na universidade”, in Freud: Aproximações. Recife: Universitária da Ufpe.

. (1995) “O Deus de Freud”, in Freud: Aproximações. Recife: Universitária da Ufpe.

(1994) "A questão da diferença e do sujeito no horizonte filosófico da crítica da racionalidade moderna.”. Síntese — Nova Fase, v.21, fascículo 55. Belo Horizonte, p.449-477.

RORTY, R. (1991) Essays on Heidegger and others. Philosophical Papers, v. 2. Cambridge: University Press.

VAZ, H. C. L. (1896) “Linguagem da experiência de Deus”, in Escritos de filosofia - 1. Problemas de fronteiras. São Paulo: Loyola.

Zeferino Rocha

zephyrinus@globo.com 